\title{
Introduction to a Fuel Continuous Mixer for Marine
}

\section{Diesel Engines' Application}

\author{
Dang Van Uy, Nguyen Dai An and Tran The Nam \\ Marine Engineering Department, Vietnam Maritime University, Haiphong City 180000, Vietnam
}

\begin{abstract}
To use the renewable fuels for marine field is still very limited due to the need of newly developed technology, highly requested safety (for gas fuel) and high price of biodiesel. Therefore, with some advantages, such as: simple producing process, reasonable price and simple modification technology needed, the blended SVO (straight vegetable oil) is recommended as suitable fuel for the marine application. Even though, there are some disadvantages of the blended SVO, such as a weak stability, layer separation in low temperature and some others. In order to apply the blended SVO as alternative fuel for marine diesel engines without the mentioned disadvantages, the paper will introduce a method to design and produce a fuel continuous mixer to make a blended SVO (palm oil).
\end{abstract}

Key words: Fuel continuous mixer, blended SVO, palm oil, alternative fuel.

\section{Introduction}

With great advantages over other types of engines, the diesel engine is being widely used in many fields such as onshore transportation, maritime transportation, agriculture machinery and so on. Yearly, however, these diesel engines used a million tons of DO (diesel oil) and also discharge to the environment a lot of toxic emissions that cause pollution to the atmosphere and make the sea level rising [1]. How to control these emissions is one of the most important tasks that people on over the world have to face off, including Vietnam. The IMO (International Maritime Organization) has recommended that the gas fuel (LNG) and the bio-fuel should be selected as alternative fuel for marine application in the future. But, in near future, the gas fuel and biodiesel are not visible to use as fuel for marine diesel engines due to the need of a new technology and very high safety for the gas fuel application on board ships and non-competitive price of the biodiesel. To avoid the above mentioned disadvantages of the gas fuel and biodiesel, the SVO (straight vegetable oil) and its blended fuel is best

Corresponding author: Dang Van Uy, Ph.D., professor, research fields: maritime engineering sciences and ship's technology.E-mail: dvuy@hn.vnn.vn. choice to use as alternative fuel for marine diesel engines in near future. However, there should need a proper modification of the fuel supply system of a diesel engine in order to avoid a phenomenon so called "separation" of the blended fuel. In this paper, there will introduce a method to create a fuel continuous mixing system (or fuel continuous mixer) to make a blended fuel or mixed fuel (SVO and DO) used as alternative fuel for marine application.

\section{A Concept of a Mixing Fuel and Continuous Mixing Method}

In the maritime field, the heavy fuel (Marine Diesel Oil or Intermediate Fuel Oil) is produced by mixing (blending) the diesel oil No.2 (DO) with the residual fuel and the same method can also be used to produce a blended fuel (straight vegetable oil-SVO with the diesel oil) for marine application. Some investigation results show that to use a blended fuel of SVO as alternative fuel for marine diesel engines is visible due to reducing toxic gases from the exhaust gas to the environment. However, there must overcome some problems, such as: weak stability of the blended fuel and it is also tending to be separated in layers. Normally, the blended fuel is made in a factory in 
batches and then it will be transported to transportation means. However, this method cannot be applied to make a blended fuel (SVO) for marine diesel engines. Therefore a continuous mixing method is a good choice.

The continuous mixing method to make a blended fuel is that the mass of input fuels is equal to that of mixed fuel output and after mixing the mixed fuel is continuously supplied to a diesel engine. So, a question is that how can we design the fuel continuous mixer to ensure the quality and the requirements of safety, stability of a mixed fuel. Fig. 1 presents a schedule of the fuel continuous mixer used on board ship to make a blended fuel (SVO and DO) for inland waterway fleet in Vietnam [2].

Therefore the complex fuel continuous mixer consists of two parts: the mechanical part and electronic control part. The mechanical part or the fuel continuous mixer will be taken into a design stage and the electronic control system will also be presented briefly in the following items.

\section{Development of a Theory to Design Fuel Continuous Mixer}

Based on the theory of mixing fluid and the requirements of the fuel quality for marine diesel engines $[3,4]$, the authors have developed a theoretical method to design the fuel continuous mixer. The quality of a mixed fuel can be understood on base of a level of homogeneousness of mixed fluids. The higher is degree of homogeneousness, the better is quality of a mixed fuel. To assess the quality of mixed fluid or effectiveness of the continuous mixer, it normally has to use a concept called a "mixing time". So, in general, the quality of the fuel continuous mixer is defined as following [3]:

$$
Q=\mathrm{f}(t, V, N, \mu, \text { impeller type) }
$$

where: $Q$ - quality of mixing; $t$-mixing time [s]; $V$-volume of mixing fluid $\left[\mathrm{m}^{3}\right] ; N$-speed of impeller [rpm]; $\mu$-dynamic viscosity [cP].

To ensure the quality of a mixing process, a flow pattern produced by the impellers must be selected properly. Following up with this idea, the type of impeller has to be chosen and then the fluid flow pattern, as well as the mixing mechanism, is presented in Fig. 2. In this article, a properly selected type of impeller is the flat blade turbine, because it can create two zones of a fluid flow: one is above and other is below the impeller. Thanks to such arrangement, the mixing quality will not be affected by the input of fluids.

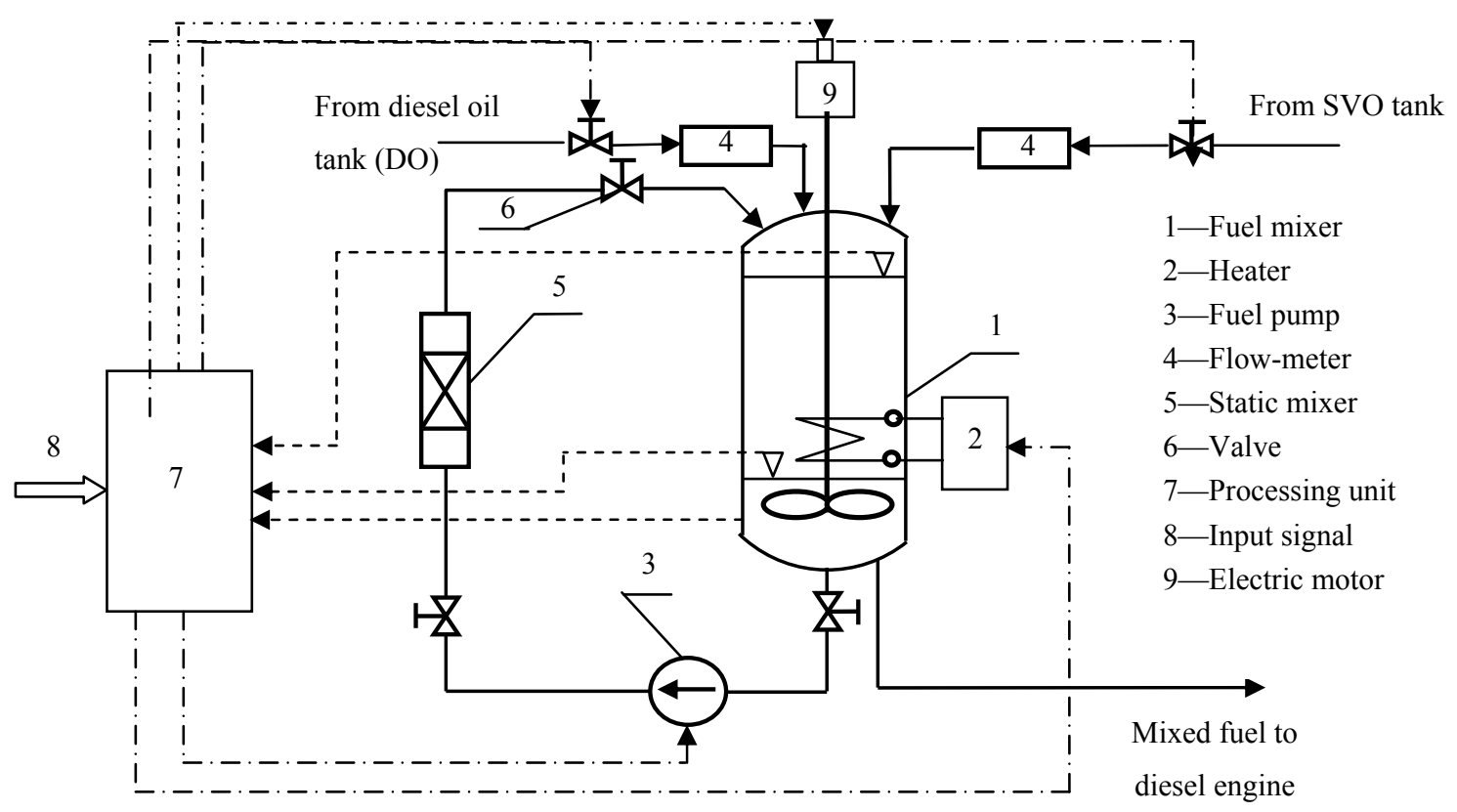

Fig. 1 Schedule of fuel continuous mixer. 


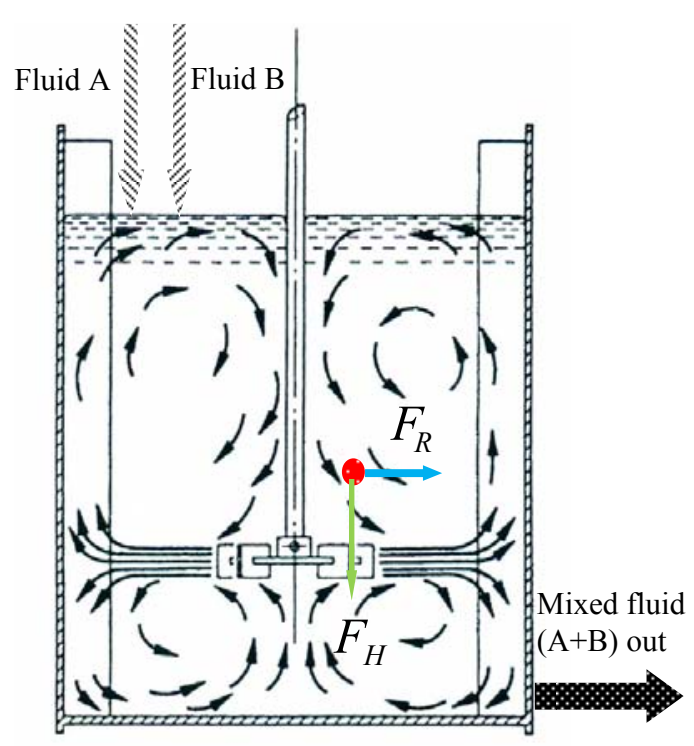

Fig. 2 Mechanism of fluid continuous mixing.

For the fuel continuous mixer, the input of fluids must be equal to output one and is also equal to the fuel consumption of a diesel engine.

$$
Q_{\text {in }}=Q_{\text {out }}=G_{f}=N_{e} \cdot g_{e} \quad[\mathrm{~kg} / \mathrm{h}]
$$

where: $Q_{\text {in }}$ and $Q_{o u t}$ - input and output of fluids respectively $\left[\mathrm{kg} / \mathrm{h}\right.$ or $\left.\mathrm{m}^{3} / \mathrm{h}\right] ; N_{e}$-output of diesel engine $[\mathrm{kW}] ; \quad g_{e}-$ specific fuel consumption $[\mathrm{kg} / \mathrm{kWh}]$.

According to the fluid mixing theory, the mixing quality depends on the mixing time. Furthermore, the mixing time is a function of a circulation time of fluid inside mixing tank. Therefore, in order to assess the mixing quality, the number of fluid circulation must be taken into consideration. For a single-phase liquid in a mixing tank with some baffles and small impeller, the relationship between mixing time and circulation time is as follow $[5,6]$ :

$$
t_{m}=4 t_{c} \quad[\mathrm{~s}]
$$

where: $t_{m}$-mixing time $[\mathrm{s}] ; t_{c}$ - circulation time and it can be determined by a formula as: $t_{c} \approx\left(\frac{\rho \cdot N^{2} d^{2}}{\Delta \rho \cdot g \cdot H}\right)^{a}, \rho$-density of mixed product; $\Delta \rho$ - difference in density between the liquids to be mixed; $N$-number of revolutions of impeller in unit time [rpm]; $d$-diameter of impeller [m]; $H$-height of liquid in mixing tank; $g$ - gravity acceleration $\left[\mathrm{m} / \mathrm{s}^{2}\right]$; $a$-constant depending on a type of impeller and $a=$ -0.25 to -0.35 .

Let take any element of mixed product to be considered and found that an element of mixed product has a going way from the top to the bottom of mixing tank as showed in the Fig. 2 and the element of a mixed product is affected by two forces. One is the centrifugal force $F_{R}$ and another is a sum of the gravity force and additional force created by liquid moving down due to output of the mixed product. Based on the above analysis, it can summarize that the element of a mixed product will be affected mainly by the force created due to the product level moving down with a velocity $/ v_{\text {down }} /$. Therefore, a remaining time of the product element inside the mixing tank can be calculated as follow:

$$
t_{\text {remain }}=\frac{H}{v_{\text {down }}}=\frac{V_{\tan k}}{G} \quad[\mathrm{~s}]
$$

In which: $t_{\text {remain }}$ - remaining time of mixed product in mixing tank [s]; $H$-height of mixing product [m]; $v_{\text {down }}$ - velocity of the product level moving down $[\mathrm{m} / \mathrm{s}] ; V_{\tan k}$-volume of mixing tank $\left[\mathrm{m}^{3}\right] ; G$-flow of mixed product output $\left[\mathrm{m}^{3} / \mathrm{s}\right]$. However, Eq. (4) is a function of the dimension of the mixing tank, so the remaining time can be determined as follow:

$$
t_{\text {remain }}=\frac{C \cdot \pi \cdot D^{2} \cdot H}{4 \cdot G} \quad[\mathrm{~s}]
$$

and

$$
G=\frac{g_{e} \cdot N_{e}}{3,600 \cdot \rho} \quad\left[\mathrm{m}^{3} / \mathrm{s}\right]
$$

Here: $D$-diameter of mixing tank $[\mathrm{m}] ; g_{e}$ - specific fuel consumption of a diesel engine $[\mathrm{g} / \mathrm{kWh}]$; $\rho$-density of mixed product or fuel $\left[\mathrm{kg} / \mathrm{m}^{3}\right]$; C-storage coefficient of tank complying with classification rules with value from 1.5 to 2 .

The remaining time $/ t_{\text {remain }} /$ is a key factor that must be taken into consideration during design of the fuel continuous mixer. Therefore, the condition required for successful design of the fuel continuous mixer is that 
the mixing time of a designed fuel mixer must be smaller than 2 to 3 times of remaining time of product.

$$
t_{m} \leq(2 \div 3) t_{\text {remain }}
$$

For design application, this must use shape factors from $\mathrm{S} 1$ to $\mathrm{S} 9$ as defined in Table 1 and Fig. $3[5,6]$.

Designing of the fuel continuous mixer means that it has to calculate all the parameters as mentioned in the Table 1, as well as to meet the condition as mentioned in Eq. (7). To complete design process, it must go through several stages which should need a computer support for calculation. A calculation algorithm of mixer parameters is presented in Fig. 4.

\section{Application}

\subsection{Designing the Fuel Continuous Mixer}

Let moving to apply the above theory to design a fuel continuous mixer to make a mixed fuel that consists of the PO (palm oil) and DO (diesel oil) as alternative fuel for marine application. A marine diesel engine selected to be an investigation object is HANSHIN6LU32 (Japan). The diesel engine is normally used as marine main engine with capacity from 1,500 to 2,500 DWT. The specifications of this diesel engine are shown in the Table 2 and physical features of the palm oil in Table 3.

Now, on a base of the algorithm and the technical data of diesel engine 6UL32 together with the physical features of palm oil and diesel oil, the required parameters of the fuel continuous mixer is calculated as presented in Table 4 and its technical drawing is showed in the Fig. 5.

Table 1 Shape factors.

\begin{tabular}{lll}
\hline Shape factor & Ratio & Values \\
\hline S1 & T/D & 3 \\
S2 & Z/D & $0.75-1.3$ \\
S3 & L/D & 0.25 \\
S4 & D/W & 5 \\
S5 & T/B & 6 \\
S6 & H/D & $2.7-3.9$ \\
S7 & Number of impeller & 6 \\
S8 & Pitch/angle & 0 deg \\
S9 & Number of baffles & 4 \\
\hline
\end{tabular}

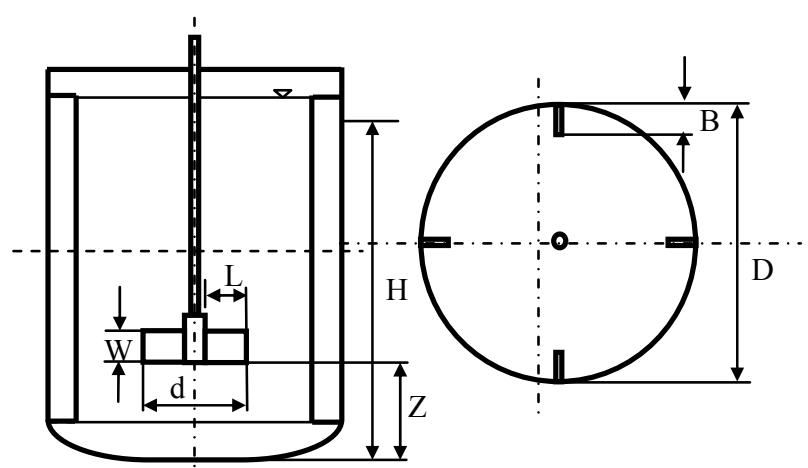

Fig. 3 Shape parameter of mixer.

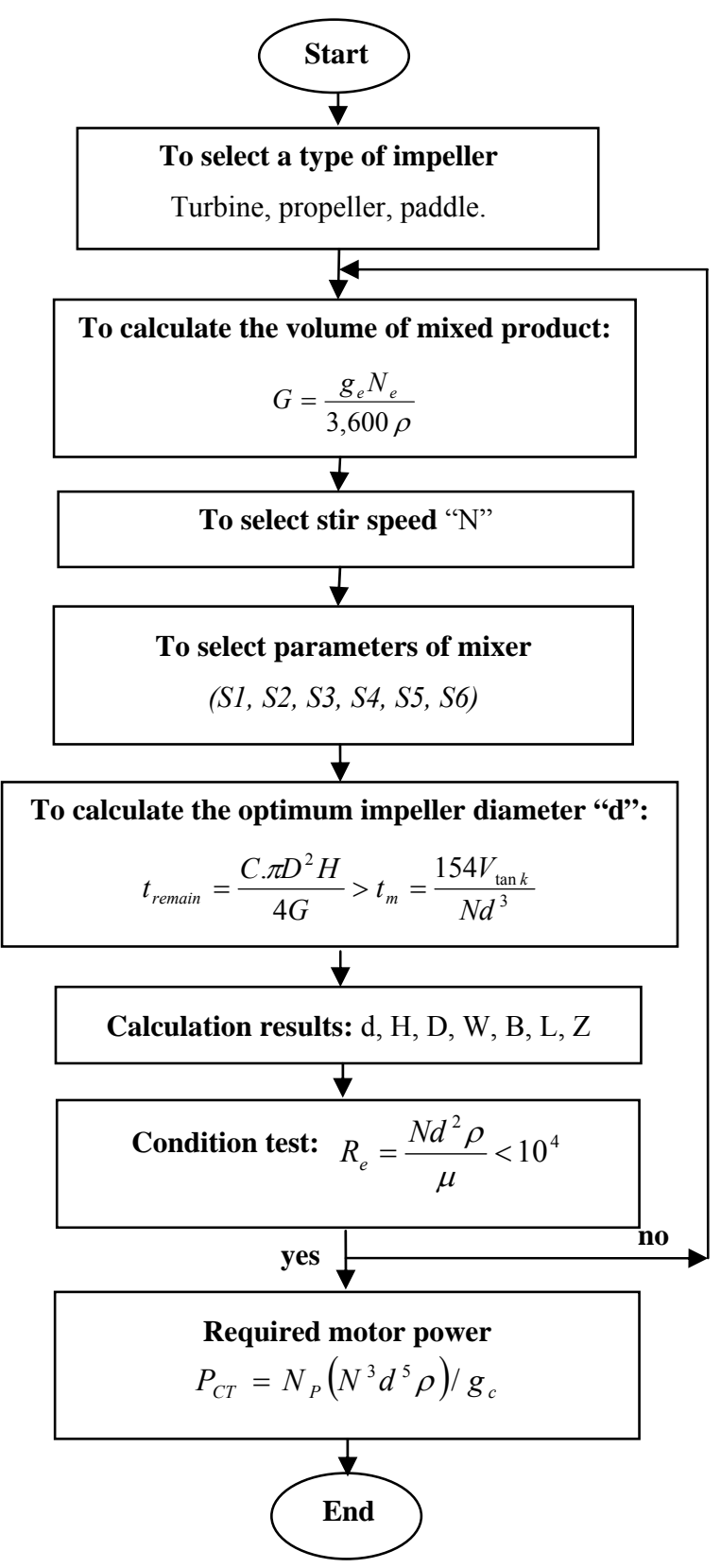

Fig. 4 Calculation algorithm of mixer parameters. 
Table 2 Technical data of diesel engine.

\begin{tabular}{ll}
\hline Technical parameters & Values \\
\hline Number of cylinders & 6 \\
Revolution $[\mathrm{rpm}]$ & 340 \\
Effective power $[\mathrm{kW}]$ & 970 \\
Cylinder bore $[\mathrm{mm}]$ & 320 \\
Stroke $[\mathrm{mm}]$ & 510 \\
Specific fuel consumption $[\mathrm{g} / \mathrm{kWh}]$ & 200 \\
Max. pressure $\left[\mathrm{kg} / \mathrm{cm}^{2}\right]$ & 90 \\
\hline
\end{tabular}

Table 3 Physical features of palm oil.

\begin{tabular}{lll}
\hline \multirow{2}{*}{ Features of fuel } & \multicolumn{2}{c}{ Kind of fuel } \\
\cline { 2 - 3 } & Palm oil & Diesel oil \\
\hline Density & 0.9225 & 0.8464 \\
Dynamic viscosity at $40{ }^{\circ} \mathrm{C}[\mathrm{cP}]$ & 79.15 & 5.53 \\
Low specific heat $[\mathrm{Kcal} / \mathrm{kg}]$ & 10,325 & 10,750 \\
Cetan number & 52.92 & 42.89 \\
\hline
\end{tabular}

Table 4 The parameters of fuel continuous mixer.

\begin{tabular}{|c|c|c|c|}
\hline $\begin{array}{l}\text { Tank diameter } \\
D[\mathrm{~m}]\end{array}$ & $\begin{array}{l}\text { Impeller diameter } \\
d[\mathrm{~m}]\end{array}$ & $\begin{array}{l}\text { Number of } \\
\text { blades }\end{array}$ & $\begin{array}{l}\text { Width of } \\
\text { impeller } \\
W[\mathrm{~m}]\end{array}$ \\
\hline 0.6 & 0.2 & 6 & 0.05 \\
\hline $\begin{array}{l}\text { Length of } \\
\text { impeller } \\
L[\mathrm{~m}] \\
\end{array}$ & $\begin{array}{l}\text { Width of baffles } \\
B[\mathrm{~m}]\end{array}$ & $\begin{array}{l}\text { Height of } \\
\text { liquid } \\
H[\mathrm{~m}] \\
\end{array}$ & $\begin{array}{l}\text { Distance from } \\
\text { impeller to } \\
\text { tank bottom }\end{array}$ \\
\hline 0.1 & 0.06 & 1.0 & 0.2 \\
\hline
\end{tabular}

\subsection{Testing Accuracy of Design Results}

The accuracy of design is a next stage that must be confirmed. It is invisible to make a fuel continuous mixer in real scale to test a working quality due to higher invest cost and time consuming. Therefore, a scale-up method is usually used to access the accuracy of design. The scale-up method can be understood as a method to make a model system in a smaller scale in accordance with specific rules to design a production-scale system or to test accuracy of design results. The rules of scale-up method consist of the geometric similarity, the kinematic similarity, the dynamic similarity and the constant $\mathrm{P} / \mathrm{V}[3,6]$.

Due to the mentioned method, a model system of the fuel continuous mixer is made as seen in Fig. 6. The mixer is made of a transparent plastic material so that it allows designer to see all things happening during a work of the mixer.

In the simplest way, criteria for scale-up used to build up a model system are the constant $\mathrm{P} / \mathrm{V}$ and the constant impeller tip speed. So, the dimension of a model system is presented in Table 5 .

After carrying out some experiments regarding to the flow pattern, mixing time and quality of mixed product, some comments can be summarized as follows:

- The flow pattern is as good as expected;

- The mixing time is from 35 seconds to 87 seconds needed to make the mixed fuel PO5 to PO20 respectively;

- Quality of the mixed fuel is good.

\subsection{Electronic Control System}

The requirements regarding to safety issues are always requested by regulations of SOLAS 74 and local

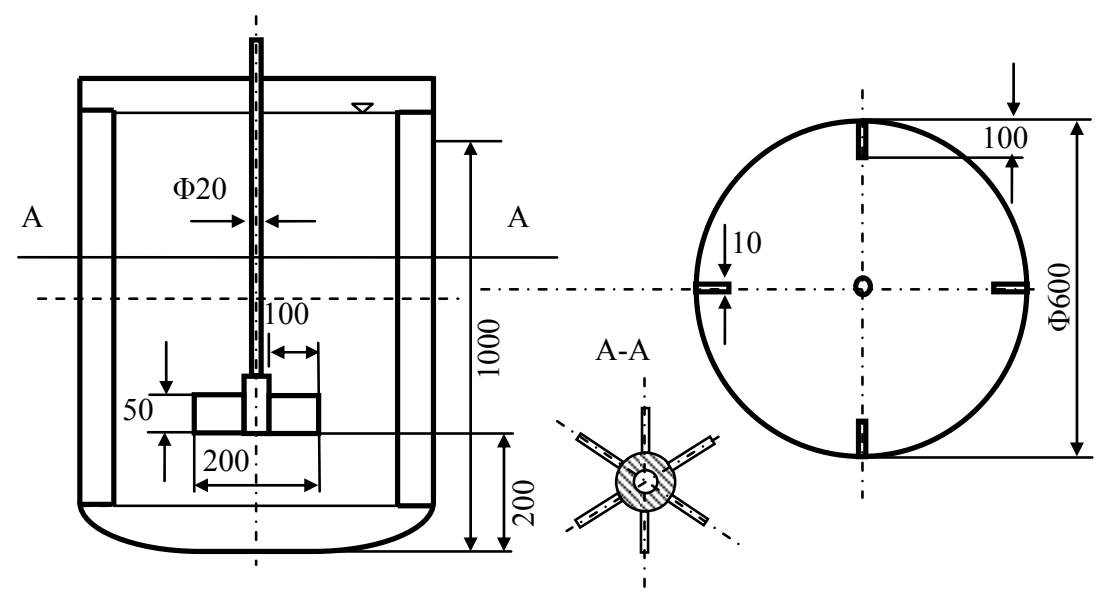

Fig. 5 Technical drawing of fuel continuous mixer. 


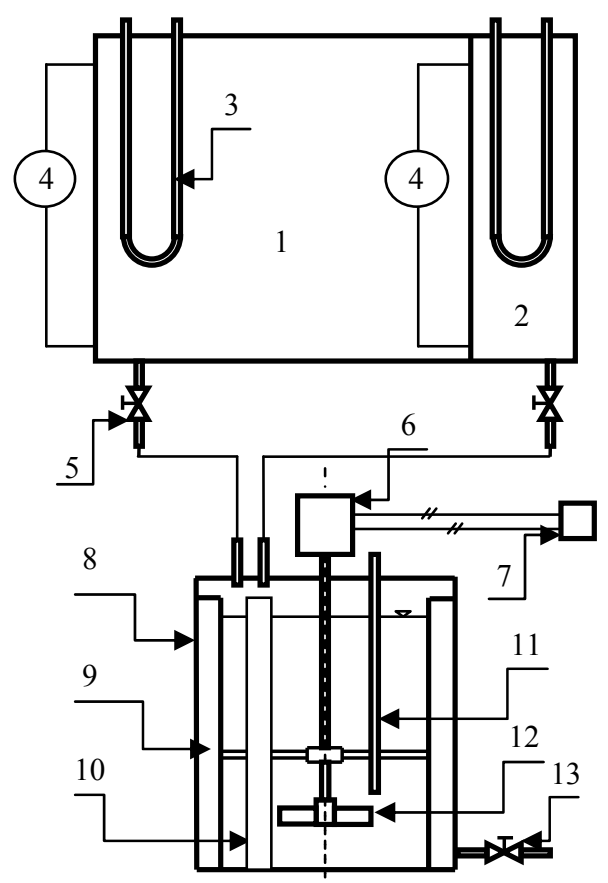

1 -DO tank

2-SVO tank

3 - Heater

4-Level check

5 -Follow adjusting valve

6-Electrical motor

7-Revolution regulator

8-Fuel continuous mixer

9- Tank baffles

10 - Level indicator

11 - Heater inside mixer

12-Impeller

13-Mixed fuel output

Fig. 6 Model test of fuel continuous mixer and its model system.

Table 5 The dimension of model system.

\begin{tabular}{|c|c|c|c|c|c|c|c|}
\hline $\begin{array}{l}\text { Tank diameter } \\
D[\mathrm{~m}]\end{array}$ & $\begin{array}{l}\text { Impeller } \\
\text { diameter } \\
d[\mathrm{~m}]\end{array}$ & $\begin{array}{l}\text { Length of } \\
\text { impeller } \\
L[\mathrm{~m}]\end{array}$ & $\begin{array}{l}\text { Width of } \\
\text { baffles } \\
B[\mathrm{~m}]\end{array}$ & $\begin{array}{l}\text { Number of } \\
\text { blades }\end{array}$ & $\begin{array}{l}\text { Height of liquid } \\
H[\mathrm{~m}]\end{array}$ & $\begin{array}{l}\text { Width of } \\
\text { impeller } \\
W[\mathrm{~m}]\end{array}$ & $\begin{array}{l}\text { Distance from } \\
\text { impeller to tank } \\
\text { bottom }[\mathrm{m}]\end{array}$ \\
\hline 0.30 & 0.10 & 0.05 & 0.03 & 6 & 0.5 & 0.025 & 0.1 \\
\hline
\end{tabular}
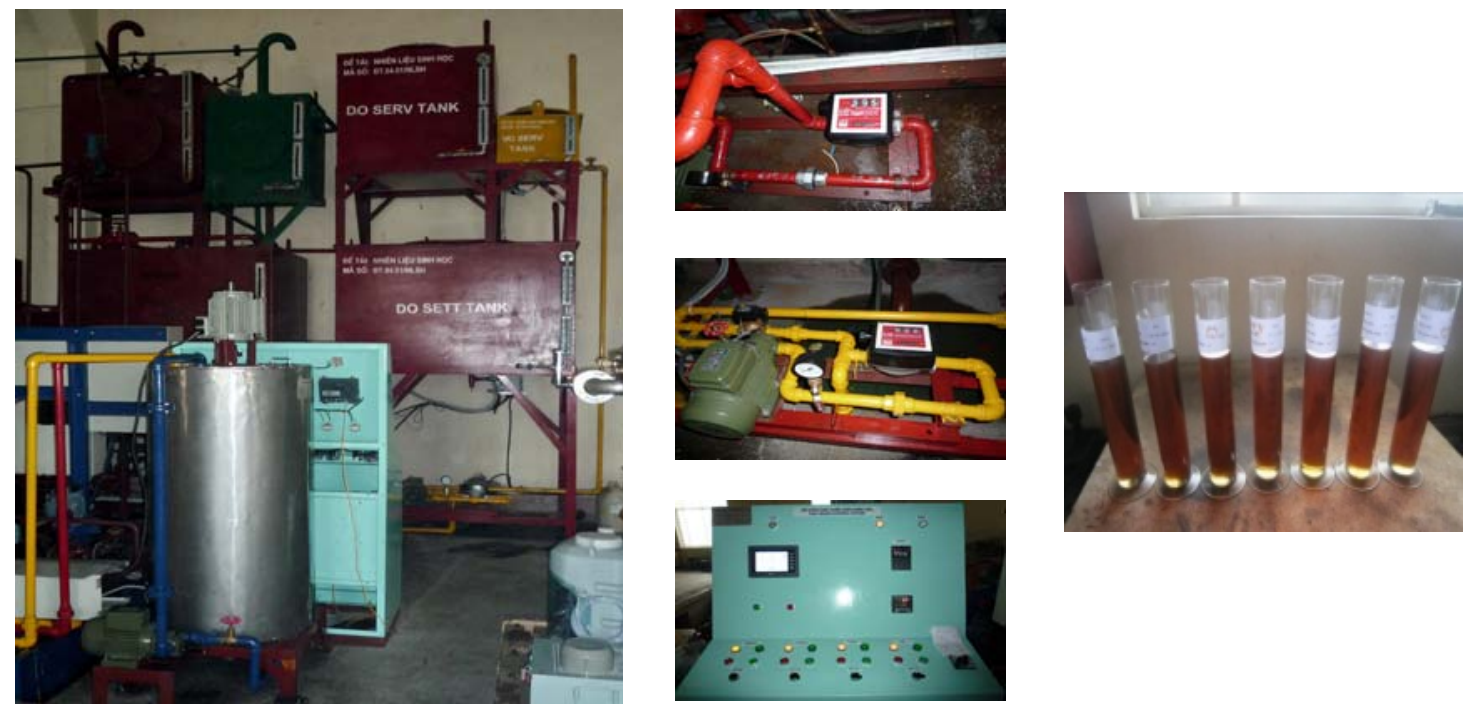

Fig. 7 Real production system and samples of mixed fuel.

maritime authority. So the electronic control system is needed to guarantee the mixed fuel quality, the correction of SVO's percentage in the mixed fuel and the safety regarding to fire during working process of the mixer. To design the electronic control system, there used a programming technology in the PLC [7].

\section{Real Production System of Fuel Continuous Mixer}

The testing results of the model system confirm 
basically the accuracy of design stage, then on a base of the parameters as showed in Table 4, the real fuel continuous mixer has been made. The fuel mixer then was installed in the fuel supply system of the marine diesel engine 6UL32 at the Center for Marine Diesel Engine Research (Vietnam Maritime University). The real production system and some samples of the mixed fuel are showed in Fig. 7.

\section{Conclusion}

The fluid continuous mixing is not new but the fuel continuous mixer applied in marine sector is very few or even not yet seen. As demanded on using the straight vegetable oil as alternative fuel for the marine diesel engines, a group of researchers has been researching and developing the fuel continuous mixer and being applied for marine application. There are some conclusions as follows:

- The idea which has been developed as mentioned above is potential method to design and make a fuel continuous mixer for marine application;

- The quality of the mixed fuel made by the fuel continuous mixer is complied with the requirements of the marine fuel;

- The real system of the fuel continuous mixer is well acceptable to be applied for marine application.

It is hopeful that the fuel continuous mixer will be applied and installed widely onboard ships in near future.

\section{References}

[1] FPA-U.S. Environmental Protection Agency. 2002. "A Comprehensive Analysis of Biodiesel Impacts on Exhaust Emissions, Draft Technical Report."

[2] Dang Van Uy. 2015. "A Study on Conversion of Marine Diesel Engines Using Blended Palm Oil for Inland Waterway Vessels in Vietnam." Journal of Shipping and Ocean Engineering (5): 9-19.

[3] Jan Gerrit Van De Vusse. 2010. Mixing by Agitation of Miscible Liquids. Rotterdam, Netherland.

[4] Kees Kuiken 2008. Diesel Engines for Ship Propulsion and Power Plants, Part I, Target Global Energy Training, Onnen, The Netherlands.

[5] John Frank Pietranski. 2012. Mechanical Agigator Power Requirements for Liquid Batches; PDH Center; 5272 Meadow Estaes Drive.

[6] Chapter 6 Mixing, Dalian University of Technology.

[7] Mixing and Agitation, Process Automation Control (PAControl). 